\title{
Population genetic structure of the Culex pipiens (Diptera: Culicidae) complex, vectors of West Nile virus, in five habitats
}

\author{
Andrea L. Joyce ${ }^{1 *}$, Etienne Melese ${ }^{2}$, Phuong-Thao $\mathrm{Ha}^{3}$ and Allan Inman ${ }^{4}$
}

\begin{abstract}
Background: The Culex pipiens complex consists of several morphologically similar, closely related species. In the United States, CX. pipiens L. is distributed North of $39^{\circ}$ latitude, while $C X$. quinquefasciatus Say occurs South of $36^{\circ}$ latitude; a hybrid zone occurs between these two latitudes including in the Central Valley of California. Members of the $C x$. pipiens complex and their hybrids are vectors for West Nile virus (WNv). Hybrid offspring of $C X$. pipiens and $C x$. quinquefasciatus have been found to have enhanced transmission rates of WNv over those of pure populations of each species. We investigated whether hybrids of $C x$. pipiens and $C x$. quinquefasciatus occurred more frequently in any of five habitats which were dairies, rural, suburban, and urban areas, and wetlands. In addition, the proportion of alleles unique to $C x$. quinquefasciatus and $C x$. pipiens found in each habitat-associated population were determined.
\end{abstract}

Methods: Amplified fragment length polymorphism (AFLP) markers were used to compare the population structure of the $C$ x. pipiens complex from each habitat to geographically distant populations considered pure $C x$. pipiens and $C X$. quinquefasciatus. Structure analyses were used to assign individuals to either $C x$. pipiens, $C x$. quinquefasciatus, or hybrids of the $C x$. pipiens complex. The ancestry of hybrids (F1, F2, or backcrossed) in relation to the two parent populations was estimated for each Central Valley population. Loci unique to the pure $C x$. pipiens population and the pure $C X$. quinquefasciatus population were determined. The proportion of loci unique to $C x$. pipiens and $C x$. quinquefasciatus populations were subsequently determined for each population from the five Merced habitats and from the Oroville California population. The unique loci found in Merced populations and not in $C$. pipiens or $C x$. quinquefasciatus were also determined. A principal components analysis was run, as was an analysis to determine loci under putative selection.

Results: The Structure Harvester analysis found $K=3$, and the Culex pipiens complex mosquitoes formed a genetic cluster distinct from $C x$. quinquefasciatus and $C x$. pipiens. Individuals collected from each habitat were nearly all hybrids. However, Cx. pipiens complex collected near dairies had more individuals categorized as $C$. pipiens than collections from the other habitats. None of the mosquitoes collected in Merced or Oroville were considered pure Cx. quinquefasciatus. Significant genetic divergence was detected among the $C$. pipiens complex from the five habitats in Merced; $C$. pipiens complex mosquitoes from dairies were divergent from the urban and suburban populations. New Hybrids analysis found that individuals from all five Merced habitat-associated populations and the population from Oroville were primarily categorized as hybrids backcrossed to the Cx. pipiens population. Finally, all five habitat-associated populations shared more alleles with $C x$. pipiens than with $C$. quinquefasciatus, even though the pure $C X$. quinquefasciatus population was more geographically proximate to Merced. Results from the principal component analysis, and the occurrence of several unique loci in Merced populations, suggest that $C$. pipiens molestus may also occur in the habitats sampled.

(Continued on next page)

\footnotetext{
* Correspondence: ajoyce2@ucmerced.edu

${ }^{1}$ Public Health, University of California Merced, 5200 North Lake Road,

Merced, CA 95343, USA

Full list of author information is available at the end of the article
} 
(Continued from previous page)

Conclusions: Nearly all mosquitoes in the five habitats in Merced in the Central Valley of California area were hybrids of $C$. pipiens and Cx. quinquefasciatus, consisting of hybrids backcrossed to $C$. pipiens. Habitat-associated mosquitoes collected near dairies had more individuals consisting of pure CX. pipiens, and no mosquitoes from Merced or Oroville CA classified as pure $C x$. quinquefasciatus. The genetic distances among $C x$. pipiens and $C x$. quinquefasciatus, and hybrid populations agree with previous studies using other molecular markers. $C x$. pipiens hybrids in Merced shared more alleles with $C$. pipiens than CX. quinquefasciatus which was unexpected, since Merced is geographically closer to the northern limit of $C$. quinquefasciatus distribution. Culex pipiens molestus may occur in more habitats in the Central Valley than previously suspected, which warrants further investigation. Future studies could investigate the vector competence of hybrids backcrossed to either $C$. pipiens or $C$. quinquefasciatus parent for their ability to transmit West Nile virus.

Keywords: AFLPs, Culex pipiens, Culex quinquefasciatus, Culex pipiens molestus, Hybrids

\section{Background}

The Culex pipiens species complex consists of several morphologically similar closely related mosquito species involved in the transmission of West Nile virus [1]. West Nile virus (WNv), originally described from Uganda and introduced on the East Coast of the United States in 1999, spread rapidly across North America and reached the West Coast in several years. West Nile virus is enzootic, primarily contained in a bird-mosquito transmission cycle with humans being incidental hosts, although prevention of human infection with West Nile remains a public health concern where the virus has been introduced [2].

In the United States, Culex pipiens L. and Cx. quinquefasciatus Say are introduced species, with $C x$. pipiens generally found North of $39^{\circ}$ latitude, and Cx. quinquefasciatus South of $36^{\circ}$ latitude; the region between these latitudes which includes the Central Valley of California is a contact zone where hybrids of $C x$. pipiens and $C x$. quinquefasciatus occur [3-6] (Fig. 1). One ecological factor in California which contributes to hybrid formation and maintenance of the hybrid zone is that $C x$. pipiens inhabits cooler northern latitudes and undergoes a winter reproductive diapause, while $C x$. quinquefasciatus resides in more southern latitudes and can overwinter without diapausing. Both $C x$. pipiens and $C x$. quinquefasciatus are efficient vectors of $\mathrm{WNv}$ [7], but the two species differ in their host preferences. Cx. pipiens host feeding preference is primarily ornithopihlic $[4,8]$, and $C x$. quinquefasciatus feeds on both birds and mammals, which can bridge the transmission of $\mathrm{WNv}$ between avian and mammalian hosts [9-11]. In addition, another very closely related member of the complex, Culex pipiens molestus, is reported in some areas of the United States, and typically inhabits primarily underground areas such as sewers and basements [12, 13], while in Europe $C x$. pipiens molestus hybrids have been found underground as well as aboveground in animal shelters $[8,14]$.

The morphological identification and separation of members of the Culex pipiens species complex is difficult. Prior to genetic studies, the primary morphological method used to separate these two species was the DV/D ratio of male genitalia [15]. Molecular studies have since been developed such as rapid genetic assays which can be used to distinguish species within the complex [16-18], and the ace-2 gene can be useful to distinguish some populations more than others [16]. Culex pipiens and Cx. quinquefasciatus are known to hybridize. Hybrids of the two mosquito species might have biological traits of both parent species, which could broaden their host preference and increase the transmission and infection rates of West Nile virus $[19,20]$. Hybrids have been challenging to identify as well. For example, neither the DV/D ratio nor the ace- 2 gene could

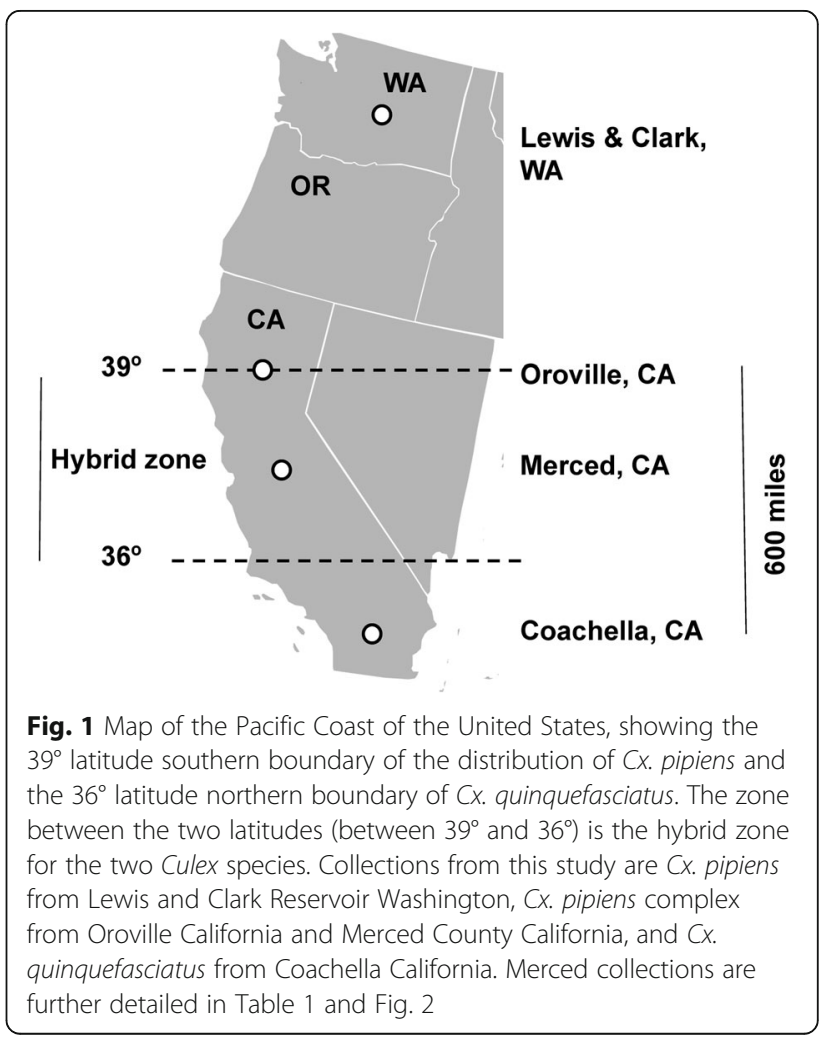


distinguish hybrid populations of the $C x$. pipiens complex near Fresno, California [5].

Hybrids of $C x$. pipiens and $C x$. quinquefasciatus have been demonstrated to have higher transmission rates of $\mathrm{WNv}$ than those of each parent species [21]. For example, crosses of male $\times$ female $C x$. pipiens had offspring with a $6 \% \mathrm{WNv}$ transmission rate after a 13-14 d extrinsic incubation period (EIP), while progeny of male $\times$ female $C x$. quinquefasciatus crosses had a $63.4 \%$ transmission rate [21]; hybrid offspring of female $C x$. quinquefasciatus $\times$ male $C x$. pipiens had even higher transmission rates (80.3\%), while hybrids of female $C x$. pipiens and male $C x$. quinquefasciatus had a $62 \%$ transmission rate [21]. Similarly, hybrid offspring from $C x$. quinquefasciatus or $C x$. pipiens crossed with $C x$. pipiens molestus had higher transmission rates than those from offspring of pure parental crosses. Hybrids of the Cx. pipiens complex are potentially a greater threat to public health if they have higher transmission rates of West Nile virus than offspring from pure parental crosses.

The proportion of hybrids and the WNv transmission rate have been investigated in the hybrid zone of $C x$. pipiens and $C x$. quinquefasciatus in the Central Valley of California. Using the DV/D ratio measurement of genitalia, mosquitoes identified as the $C x$. pipiens complex from dairy lagoons in Merced County consisted of $11 \%$ Cx. pipiens complex hybrids and $89 \% C x$. pipiens [22]. Another study using the DV/D ratio to examine individuals from Merced found that $32 \%$ of the $C x$. pipiens complex were classified as hybrids, $62 \%$ as $C x$. quinquefasciatus and $6 \%$ were $C x$. pipiens [3]. Variation in the percentage of $C x$. pipiens to $C x$. quinquefasciatus was found among multiple sites in Stockton, CA, suggesting population structure can occur on a relatively small scale [3]. Using field-collected mosquitoes from Fresno County and the ace-2 gene PCR assay for identification, 22\% (98/442) of the Cx. pipiens complex collections were identified as hybrids; these field-collected hybrids had a $20 \% \mathrm{WNv}$ infection rate (20/98 collected) compared with 21\% (58/271) of those identified as Cx. quinquefasciatus or $14 \%$ (10/73) identified as Cx. pipiens [5]. However, the same study by McAbee et al. [5] used the DV/D ratio and found 66\% (293/ 442) of individuals in Fresno classified as hybrids. In $C x$. pipiens populations from Merced to Bakersfield, WNv transmission rates varied from 12.5 to $40 \%$ and 50 to $69 \%$ after an EIP of 7 and $14 \mathrm{~d}$, while populations of 'pure' $C x$. pipiens and $C x$. quinquefasciastus from northern and southern California did not transmit West Nile virus [22]. Goddard et al. [1] found a Bakersfield population of $C x$. quinquefasciatus had a higher transmission rate of $\mathrm{WNv}(52 \%)$ after $14 \mathrm{~d}$ EIP than did those from Riverside or Orange California (19 and 36\%, respectively), while Cx. pipiens from Shasta had a $71 \%$ transmission rate after $14 \mathrm{~d}$ extrinsic incubation period [1]. The transmission rate of $\mathrm{WNv}$ for the $C x$. pipiens complex varies among these studies. However, populations from the hybrid zone have typically demonstrated higher
WNv transmission rates than pure parental populations, and transmission rates of $\mathrm{WNv}$ for $C x$. quinquefasciatus are generally greater than for $C x$. pipiens and $C x$. pipiens molestus $[1,5,21,22]$.

Habitat can influence the species composition, the abundance of hybrids, and the WNv infection rate of the $C x$. pipiens complex [23]. In other insect systems, adjoining habitats can contribute to genetically divergent populations, which has been termed ecological speciation [24, 25]. Similarly, mosquito populations with distinct host preferences can have genetic differences as well [26]. Culex pipiens and Cx. pipiens molestus can occur in different habitats in close proximity [13], demonstrating that habitat can be associated with the abundance of $C x$. pipiens complex hybrids. Culex pipiens molestus is commonly associated with underground areas such as basements and sewers, yet recently hybrids of $C x$. pipiens and $C x$. pipiens molestus have been found indoors in animal shelters [8]. In California, previous studies have focused on hybridization of $C x$. quinquefasciatus and Cx. pipiens; several studies have found evidence of Cx. pipiens molestus $[12,13]$. The role of habitat in hybrid formation for $C x$. pipiens and $C x$. quinquefasciatus has rarely been investigated [27]. Although the proportion of hybrids in the $C x$. pipiens complex was similar in urban and rural areas (34 and $36 \%$, respectively), the abundance of the $C x$. pipiens complex and the $\mathrm{WNv}$ infection rate was higher in urban low income areas than in urban middle income or in rural areas [23]. The general pattern of human WNv cases in North America has been that most cases occur in urban and agricultural (rural) habitats [28]. The Central Valley of California is largely rural, but habitats within Merced County vary greatly. Eastern Merced County has an urban corridor along a major highway and numerous dairies and potential hosts for $C x$. quinquefasciatus, while western Merced County is rural with smaller communities, agricultural areas, and extensive wetland habitat for migrating birds, the preferred hosts of $C x$. pipiens. Previous studies which included $C x$. pipiens complex mosquitoes from Merced included few samples and varied greatly in the proportion of hybrids found. Given that laboratory studies have demonstrated that pure $C x$. quinquefasciatus and its hybrids with $C x$. pipiens have higher West Nile virus transmission rates, a more thorough investigation of the $C x$. pipiens complex in the region would be beneficial.

The objective of this study was to determine the population genetic structure of $C x$. pipiens complex mosquitoes in five habitats in Merced County, which is located in the Central Valley of California. This study investigated whether a particular habitat had a higher frequency of hybrids relative to abundance of pure $C x$. quinquefasciatus or pure $C x$. pipiens. Similarly, we were interested in whether any habitat had more pure $C x$. quinquefasciatus due to its higher transmission rate of WNv than that of $C x$. pipiens. Areas or habitats found 
to have more hybrids or more $C x$. quinquefasciatus could be prioritized as targets for vector control.

\section{Methods \\ Collecting samples}

Mosquitoes from five habitats were collected in the hybrid zone of $C x$. pipiens and $C x$. quinquefasciatus in Merced County in the Central Valley of California (Figs. 1 and 2). Traps were set in four quadrants of the county; Northwest near Gustine, Southwest near Los Banos, Northeast near Hilmar and Livingston, and Southeast near Merced (Fig. 2). The distance across the sampled area in Merced County was 30 miles from North to South, and 30 miles from East to West. Mosquito samples were collected during 2012-2014. Each year, traps were set in the five habitats in each quadrant which included near dairies, rural, suburban, urban areas, and in wetlands. All traps were set in open outdoor areas with the intent to trap populations of $C x$. quinquefasciatus, $C x$. pipiens, and their hybrids; no traps were placed underground in sewers or basements, or in animal shelters, where $C x$. pipiens molestus was presumed to occur. Dairies were typically in rural areas and had nearby dairy lagoons with runoff water polluted with manure. Rural areas were farmland or countryside with less than 2500 people in the area [29]. Suburban areas were residential areas located on the outskirts of a city or town [30], while urban areas were characterized by densely developed locations with at least 2500 residents
[29]. Finally, wetlands were defined as land where water shallowly covers the soil at the surface and includes areas such as swamps and marshes [31]. Many collection site locations are sites regularly surveyed by the Merced County Mosquito Abatement District (MCMAD) surveillance program and are included in the California Vectorborne Disease Surveillance (CalSurv) database used for West Nile surveillance in California [32].

Adult female mosquitoes were trapped using CDC style light traps baited with $\mathrm{CO}_{2}$ set in the afternoon and retrieved the following morning during the months of June-October. Adult mosquitoes from traps were frozen and subsequently identified using light microscopy [33]. Culex pipiens and Culex quinquefasciatus are morphologically identical and thus classified as the Culex pipiens complex. The difficulty in distinguishing these two species morphologically, and the inconsistency of results using the DV/D ratio to separate hybrids of the two species, have led to a number of investigations using molecular markers to distinguish the two species. In Merced County, there are no other Culex species which resemble the Culex pipiens complex. Females identified as belonging to the $C x$. pipiens complex were frozen or saved in ethanol for subsequent DNA extraction. Samples were collected from 31 unique sites in Merced County (Table 1), which were classified into five habitats of interest. The following number of collection sites within Merced county were used for each of the five habitats: dairy $(n=5)$, rural $(n=9)$,

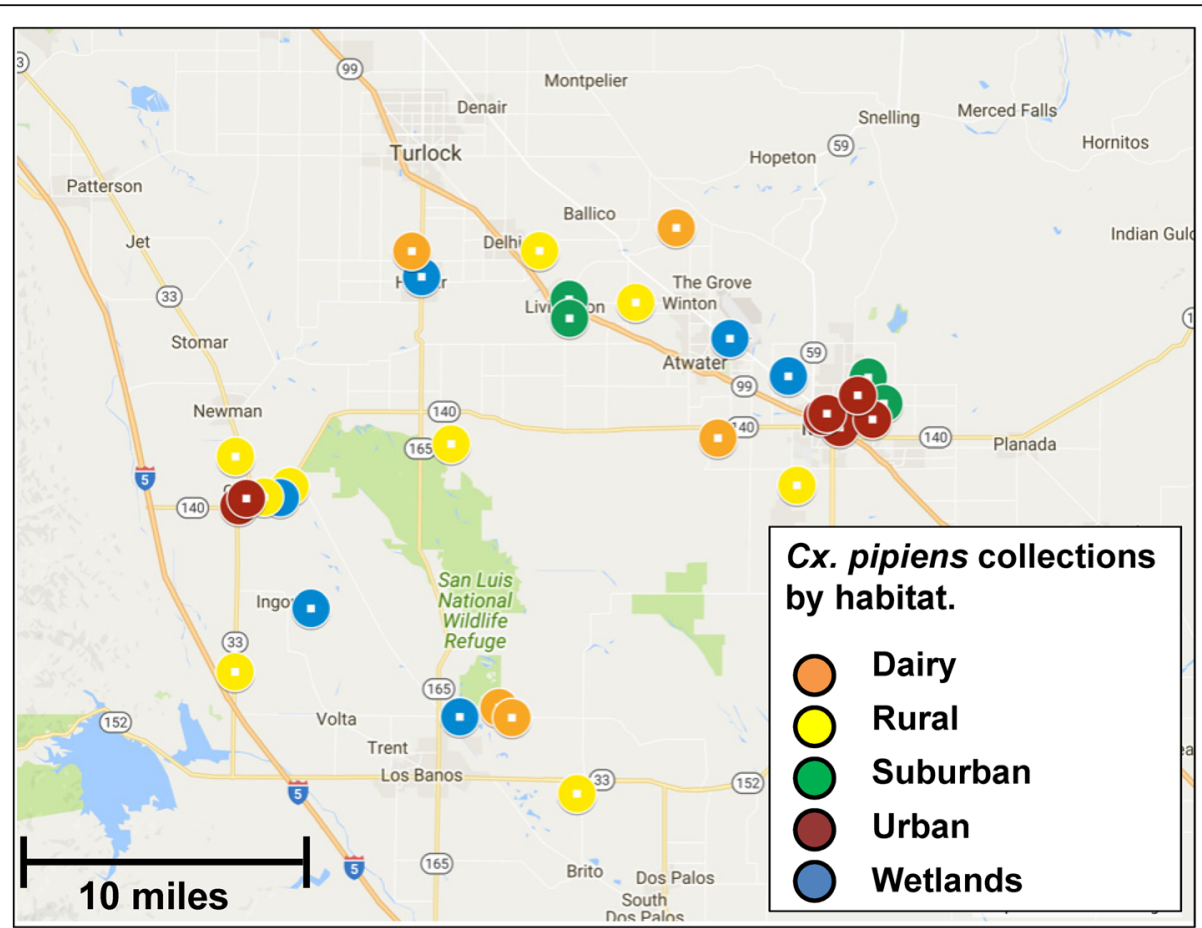

Fig. 2 Collections of the Cx. pipiens complex in Merced County, California from five habitats. The habitats include dairies, rural, suburban, urban areas and wetlands 
Table 1 Location of sample collections in Merced County by habitat

\begin{tabular}{|c|c|c|c|c|}
\hline Habitat & Site name or site code CalSurv & Map code (Fig. 2) & GPS coordinates & Individuals used \\
\hline \multirow[t]{6}{*}{ Dairy } & 000402 & D1 & $37.431944,-120.864167$ & 2 \\
\hline & 001225 & D2 & $37.44205,-120.625528$ & 42 \\
\hline & Baker Dairy & D3 & $37.105948,-120.781767$ & 9 \\
\hline & F\&A Brooks Dairy & D4 & $37.294767,-120.58755$ & 11 \\
\hline & Stevenson/Hilmar & D5 & $37.0985,-120.7701933$ & 8 \\
\hline & Total & & & 72 \\
\hline \multirow[t]{10}{*}{ Rural } & 001219 & R1 & $37.426017,-120.745781$ & 1 \\
\hline & 000407 & R2 & $37.255278,-120.992222$ & 3 \\
\hline & 000102 & R3 & $37.261667,-120.518889$ & 10 \\
\hline & 001103 & R4 & $37.389842,-120.661219$ & 11 \\
\hline & Netherton & R5 & $37.2819444,-121.0138888$ & 9 \\
\hline & 000413 & R6 & $37.045,-120.713056$ & 2 \\
\hline & Old Romero School & R7 & $37.130233,-121.0147166$ & 9 \\
\hline & Stevenson Ranch & R8 & $37.290767,-120.96598$ & 8 \\
\hline & Gustine Airport & R9 & $37.260866,-120.96598$ & 1 \\
\hline & Total & & & 54 \\
\hline \multicolumn{5}{|c|}{ Suburban } \\
\hline & 909 & S1 & $37.3375,-120.456111$ & 6 \\
\hline & 000506 & S2 & $37.393333,-120.719444$ & 16 \\
\hline & 000507 & S3 & $37.378611,-120.719444$ & 4 \\
\hline & 000403 & S4 & $37.408056,-120.85$ & 18 \\
\hline & KM's House & S5 & $37.319008,-120.4422833$ & 3 \\
\hline & Total & & & 47 \\
\hline \multirow[t]{8}{*}{ Urban } & 000916 & U1 & $37.302222,-120.481389$ & 8 \\
\hline & 001205 & U2 & $37.312183,-120.492539$ & 11 \\
\hline & 001227 & U3 & $37.310103,-120.496792$ & 4 \\
\hline & 001304 & U4 & $37.247411,-121.010942$ & 1 \\
\hline & 001301 & U5 & $37.307947,-120.452553$ & 6 \\
\hline & Sonora Pool & U6 & $37.324713,-120.465416$ & 1 \\
\hline & Sycamore & U7 & $37.252366,-120.004333$ & 4 \\
\hline & Total & & & 35 \\
\hline \multicolumn{5}{|c|}{ Wetlands } \\
\hline & 000417 & W1 & $37.338333,-120.526667$ & 3 \\
\hline & 001302 & W2 & $37.099117,-120.816314$ & 2 \\
\hline & 000005 & W3 & $37.364444,-120.578056$ & 5 \\
\hline & Gustine Water Trtmnt & W4 & $37.252817,-120.973617$ & 2 \\
\hline & Gustine Duck Club & W5 & $37.1750166,-120.947466$ & 4 \\
\hline & Total & & & 16 \\
\hline
\end{tabular}

suburban $(n=5)$, urban $(n=7)$ and wetlands $(n=5)$ (Table 1, Fig. 2). Geographical coordinates of trap locations were recorded at each sampling site (Table 1, Fig. 2).

A population of $C x$. pipiens from Washington State North of $39^{\circ}$, and one of Cx. quinquefasciatus from southern California South of $36^{\circ}$ were included in the study for comparison with samples from our five Merced habitats. The pure $C x$. pipiens population was collected from Lewis and Clark Reservoir, Washington $\left(46^{\circ} 21^{\prime} 32^{\prime \prime} \mathrm{N}\right.$, $\left.-119^{\circ} 25^{\prime} 29^{\prime \prime} \mathrm{E}\right)$ and the $C x$. quinquefasciatus population was collected from Mecca, Coachella, California $\left(33^{\circ} 34^{\prime} 47^{\prime \prime} \mathrm{N}\right.$, $-116^{\circ} 4^{\prime} 37^{\prime \prime} \mathrm{E}$ ) (Fig. 1). We obtained a population from 
Oroville in northern California which we originally planned to use as the 'pure' $C x$. pipiens population. However, the hybrid zone of $C x$. pipiens and $C x$. quinquefasciatus is now considered to extend North of its original $39^{\circ}$ latitude boundary (and North of Oroville California), so we instead chose to use the Washington State population as our pure Cx. pipiens population (Fig. 1). All mosquito samples collected and used for DNA in this study were female.

\section{DNA extraction, amplified fragmented length polymorphisms (AFLPs)}

DNA was extracted from the entire mosquito body (head, thorax, and abdomen) for all individuals using the Qiagen DNeasy Blood and Tissue kit (Venlo, Netherlands) following the protocols for animal tissue with an overnight incubation time of $\sim 24 \mathrm{~h}$ at $65{ }^{\circ} \mathrm{C}$ [34]. Final products were eluted in $100 \mu \mathrm{l}$ of AE buffer. The DNA quantity was measured using the Qubit $^{\circledR}$ dsDNA HS Assay kit (Life Technologies-Thermo Fisher Scientific, Waltham, MA, USA). The quantity of DNA in samples averaged 5-10 ng/ $\mu$ l. Only female adults were used for molecular work.

Amplified fragment length polymorphisms were produced as described by Vos et al. [35] and modified by Joyce et al. [36]. Three primer combinations were used, (i) M-CAT and E-ACG, (ii) M-CAC and E-ACT and (iii) $\mathrm{M}-\mathrm{CAC}$ and E-ACA (Table 2). Individuals from the five habitats (dairy, rural, suburban, urban and wetlands) in Merced, California and from three other locations [Mecca, Coachella, California (COA); Oroville California (ORO); and Lewis and Clark Reservoir, Washington (WA)] were all randomized on five 96-well plates for AFLP reactions. Eleven individuals were run in duplicate in order to test the error rate of the AFLP markers.

Each restriction/ligation reaction (well) consisted of the following: $0.05 \mu \mathrm{l}$ each of EcoRI and MseI, $1.1 \mu \mathrm{l}$ of T4 DNA ligase buffer, $1.1 \mu \mathrm{l}$ of $0.5 \mathrm{M} \mathrm{NaCl}, 0.55 \mu \mathrm{l}$ of diluted BSA (bovine serum albumin), $0.03 \mu \mathrm{l}$ of T4 DNA ligase, $1.0 \mu \mathrm{l}$ each of EcoRI and MseI adaptor pairs (Life Technologies-Thermo Fisher Scientific, Waltham, MA, USA), and $0.61 \mu \mathrm{l}$ of sterile distilled water. The plate with restriction/ligation reactions was held at room temperature overnight $\left(12 \mathrm{~h}\right.$ at $\left.25^{\circ} \mathrm{C}\right)$ to ensure complete digestion [37]. The amplified product was diluted 20-fold using $15 \mathrm{mM}$

Table 2 Primer combinations used for selective polymerase chain reaction of amplified fragment length polymorphisms (AFLPs), number of markers produced by each primer combination, number $<125 \mathrm{bp}$, and the percent mismatch error rate

\begin{tabular}{llllll}
\hline $\begin{array}{l}\text { Primer } \\
\text { combination }\end{array}$ & EcoR1- & Mse1- & No. of markers & Markers $<125 \mathrm{bp}$ & $\begin{array}{l}\text { Percent } \\
\text { mismatch }\end{array}$ \\
\hline 1 & ACG & CAT & 120 & $38 / 120$ & 2.0 \\
2 & ACT & CAC & 110 & $29 / 110$ & 2.0 \\
3 & ACA & CAC & 120 & $25 / 120$ & 1.6 \\
\hline
\end{tabular}

Tris- $\mathrm{HCl}$ buffer ( $\mathrm{pH}$ 8.0) containing $0.1 \mathrm{mM}$ EDTA. Preselective PCR amplification was performed on a ThermoFisher Arktik thermal cycler. Each reaction contained $15 \mu \mathrm{l}$ of AFLP preselective mix (all Life Technologies/ThermoFisher), $1 \mu \mathrm{l}$ of each amplification primer (Life Technologies), along with $4 \mu \mathrm{l}$ of the diluted restriction/ligation mixture. The PCR program for pre-selective amplification consisted of an initial warm-up of $95^{\circ} \mathrm{C}$ for 1 min followed by 20 cycles at $95{ }^{\circ} \mathrm{C}$ for $20 \mathrm{~s}, 56^{\circ} \mathrm{C}$ for $30 \mathrm{~s}$, and $72{ }^{\circ} \mathrm{C}$ for $90 \mathrm{~s}$ with a final hold at $75^{\circ} \mathrm{C}$ for $5 \mathrm{~min}$. The amplified product was diluted 20 -fold using $15 \mathrm{mM}$ Tris- $\mathrm{HCl}$ buffer (pH 8.0) containing $0.1 \mathrm{mM}$ EDTA. Selective amplification was conducted using two primer combinations. For each selective amplification, a reaction consisted of $15 \mu \mathrm{l}$ of AFLP platinum supreme mix, $1.0 \mu \mathrm{l}$ of EcoRI +3 selective primers, and $1.0 \mu \mathrm{l}$ of $M s e \mathrm{I}+3$ selective primers (all Life Technologies-Thermo Fisher Scientific Waltham, MA, USA)(Table 2). The PCR program for selective amplification consisted of an initial warm-up of $95{ }^{\circ} \mathrm{C}$ for $1 \mathrm{~min}$, 12 cycles of $95{ }^{\circ} \mathrm{C}$ for $20 \mathrm{~s}, 65^{\circ} \mathrm{C}$ for $40 \mathrm{~s}$ with a lowering of $0.7{ }^{\circ} \mathrm{C}$ per cycle, $72{ }^{\circ} \mathrm{C}$ for $90 \mathrm{~s}$, followed by 35 cycles of $95^{\circ}$ $\mathrm{C}$ for $20 \mathrm{~s}, 56{ }^{\circ} \mathrm{C}$ for $40 \mathrm{~s}, 72{ }^{\circ} \mathrm{C}$ for $90 \mathrm{~s}$, and finally a hold of $72{ }^{\circ} \mathrm{C}$ for $7 \mathrm{~min}$ before storing the samples at $4{ }^{\circ} \mathrm{C}$. Prior to capillary electrophoresis, $0.4 \mu \mathrm{l}$ of the Genescan LIZ 500 size standard and $0.9 \mu \mathrm{l}$ of HiDi formamide (all Life Technologies) were added to $1 \mu \mathrm{l}$ of the final product of each sample. The LIZ 500 size standard allows for detection of fragments between 50 and $500 \mathrm{bp}$. Sample fragments were separated using automated capillary electrophoresis by the ABI 3730 XL automated capillary DNA sequencer (Applied Biosystems-Thermo Fisher, Waltham, MA, USA).

GeneMapper version 5.0 (Life Technologies, ThermoFisher) was used to determine presence or absence of fragments. The peak detection threshold was set for each primer combination, and was typically 150 luminescent units. Each AFLP marker was considered a locus and assumed to have two possible alleles $(0=$ absent, $1=$ present $)$. Bands not present in more than one individual were eliminated (i.e. private alleles) prior to further analyses, as they were not considered informative. For samples which were run in duplicate, each marker was examined to determine whether markers were scored identically at each locus by GeneMapper, and data were used to calculate the mismatch error rate [38]. Structure 2.3.4 software [39] was used to group individuals with similar genotypes within each species. Structure uses a Bayesian algorithm to cluster individuals into $\mathrm{K}$, which is defined as the number of genetically distinct populations in a data set. Parameters used for the analyses include the following: no a priori assignment of individuals to a known population, analysis for diploid insects, a burn-in of 100,000 and 200,000 subsequent iterations, an admixture model, and independent loci.

For runs in Structure software, the number of potential populations for $\mathrm{K}$ was estimated as the number of 
geographical sampling locations plus 4 as suggested by Pritchard et al. [40]. At the completion of Structure runs, $\mathrm{K}$ was calculated for each species using Structure Harvester using the Evanno method [41, 42], to determine the most likely number of population clusters (K) for the populations sampled. A Structure analysis was first run for all populations, and $\mathrm{K}$ was estimated as the number of geographic sampling locations plus 4 [5 Merced habitats + Oroville + pure $C x$. quinquefasciatus + pure $C x$. pipiens populations ( 8 pops $+4, K=12)$ ] for the overall analysis as suggested by Pritchard et al. [40], and each iteration was run 20 times. A Structure analysis was also run for mosquitoes collected in each Merced habitat and compared to the $C x$. pipiens and $C x$. quinquefasciatus populations, as was the Oroville population. For each habitat analysis in Structure, the number of potential populations for K was estimated as the number of geographic sampling locations plus 4 (a single habitat + pure Cx. quinquefasciatus + pure $C x$. pipiens populations $=3$ populations $+4, K=7$ for each habitat analysis) as suggested by Pritchard et al. [40]. Similarly, mosquitoes collected in all five Merced habitats were compared in an additional Structure analysis (K estimated as 5 habitats $+4, K=9$ ), and examined with Structure Harvester as well. A q value of $>0.80$ from Structure was used to assign individuals to clusters while individuals with a $\mathrm{q}$ value $<0.8$ were considered admixed [13]. Structure results were used in Clumpak software to run Distruct to permutate runs to best visualize results.

New Hybrids v.1.1 software was used to examine the probability of each Cx. pipiens complex mosquito's assignment of membership into a number of groups, including pure $C x$. quinquefasciatus, pure $C x$. pipiens, F1 hybrids of the two Culex species, F2 hybrids, or backcrosses to either parent [43]. Individuals were assigned to a pure species if $\mathrm{q}>0.9$, F1 if $\mathrm{q}=\sim 0.5$, F2 if $\mathrm{q}<0.5$ for both parent species, and considered a hybrid backcross to a parent species if $0.5 \leq \mathrm{q}<0.9$. Individuals were not assigned a priori to a particular population, and runs were conducted with Jeffery like priors. One hundred thousand iterations were run and the posterior probability of each individual's assignment to the above genetic classes was determined.

An analysis of molecular variation (AMOVA) was run to compare the molecular variation of individuals of the $C x$. pipiens complex from populations collected in four regions, including $C x$. quinquefasciatus (COA), Cx. pipiens (WA), Oroville California (ORO) and all individuals from Merced California [44]. The AMOVA was run using 999 permutations, and pairwise comparisons of the genetic divergence $\left(\mathrm{F}_{\mathrm{ST}}\right)$ values between populations were made, using Bonferroni corrections for multiple comparisons. A second AMOVA was run for individuals from the 5 Merced habitat populations also using 999 permutations. Similarly, the Fst values were compared for significance between pairs of populations, with Bonferroni corrections for multiple comparisons. Analyses were run using GenAlEx 6.5 software [45]. Output from the AMOVA Fst values were used to run a principal component analysis among the eight populations using GenAlEx 6.5 .

Nei's genetic distance was determined among all 8 populations using GenDist in Phylip 3.695 [46]. A Mantel test was run to determine if genetic distance was correlated to geographical distance between populations. Since collections from each Merced habitat came from 5 to 9 sites in the county (Table 1), we chose a representative location and genetic distance for Merced to run the Mantel test between Merced and the three other collection regions. We used the genetic distance from a downtown Merced urban population (U6) for comparison with Oroville CA, $C x$. pipiens (WA) and Cx. quinquefasciatus (COA).

For $C x$. pipiens complex mosquitoes from the five habitats, the proportion of unique alleles from $C x$. quinquefasciatus (COA) and $C x$. pipiens (WA) populations was determined for each Merced mosquito. Alleles unique to $C x$. quinquefasciatus were defined as those which were present only in the pure $C x$. quinquefasciatus population and not in in the pure $C x$. pipiens population; similarly, loci unique to $C x$. pipiens were those only found in the pure $C x$. pipiens population. Unique loci from the pure $C x$. quinquefasciatus and the pure $C x$. pipiens population in each Merced mosquito were first identified. Next, the number of unique $C x$. quinquefasciatus alleles and unique $C x$. pipiens alleles were determined for individuals in each Merced habitat-associated population, and used to produce the mean proportion of $C x$. quinquefasciatus and $C x$. pipiens alleles for each of the five habitats and the Oroville population. For each habitat, we used a Chisquare goodness of fit test to compare whether the proportion of unique $C x$. pipiens: $C x$. quinquefasciatus alleles varied from a 1:1 equal distribution [47]. One-way ANOVA was then used to determine whether one habitat had a significantly higher proportion of $C x$. quinquefasciatus alleles than other habitat-associated populations. Unique alleles which were found only in the Merced habitat populations but were not found in the Oroville, the pure $C x$. quinquefasciatus or the $C x$. pipiens populations were also identified as well. Loci present in higher frequency and found in nearly half the individuals ( 30 or more) of at least 2 or more habitat-associated populations were determined, followed by unique alleles found in very low frequencies (typically in 1-10 individuals) in the Merced populations.

The software Mcheza was used to examine candidate loci that may be under selection in the habitat associated populations [48]. Mcheza is available from popgen.net, and is a selection workbench developed for dominant markers such as AFLPs. The file with presence or absence of AFLP loci was converted to the Genepop format. MCheza was run to examine which loci were Fst outliers. The following default settings were used; confidence interval 0.95 , false discovery rate of 0.1 , Theta 0.1 , 
beta-a 0.25 and beta-b 0.25 . The option of neutral mean Fst was chosen and 500,000 simulations were run. Candidate loci under positive selection, balancing selection and neutral selection were determined.

\section{Results}

\section{Collecting samples}

Female mosquitoes identified as the Culex pipiens complex were collected from 5 dairies, 9 rural, 5 suburban, 7 urban and 5 wetland sites in Merced County (Table 1, Fig. 2). Culex pipiens complex mosquitoes were generally more abundant from collections near dairies and were relatively common in rural, suburban and urban samples (Table 1). Most wetlands collections in this study yielded few $C x$. pipiens complex mosquitoes, as the wetlands sites were dominated by Culex tarsalis Coquillett.

\section{Population genetic structure: amplified fragment length polymorphisms (AFLPs)}

Amplified fragment length polymorphisms (AFLPs) were produced using 3 primer combinations (Table 2). There were 350 alleles produced for comparison of the 278 individuals from the 8 populations in the study, which included Coachella California (Cx. quinquefasciatus), 5 habitatassociated populations of $C x$. pipiens complex from Merced CA, Oroville CA (Cx. pipiens complex) and Cx. pipiens from Washington State. From Merced County, there were $72 \mathrm{Cx}$. pipiens complex mosquitoes included from dairies, 54 from rural areas, 52 from suburban areas, 35 from urban sites and 16 from wetland habitats. There were also 17 mosquitoes of pure $C x$. quinquefasciatus from Coachella, $17 C x$. pipiens complex from Oroville, and 15 pure Cx. pipiens from Washington. Fragments produced were viewed with GeneMapper 5.0 and scored as present or absent for each individual. Three primer combinations were used to produce AFLPs, resulting in 120, 110, and 120 fragments (Table 2 ). The number of fragments which were sized $<125 \mathrm{bp}$ for each primer were 38/120 for primer combination 1, 29/110 for primer 2, and 25/120 for primer 3 (Table 2). A test of the error mismatch rate for the AFLP markers for 8 individuals from Merced found that fragments had a 2, 2 and 1.6\% mismatch error rate for each of the three primers, respectively (Table 2).

The Structure analysis of all 8 populations and subsequent Structure Harvester analysis of the data found the highest Delta $K$ Evanno value at $K=9$, followed by $K=3$ (Figs. 3 and 4, Additional file 1: Figure S1). However, the result of $\mathrm{K}=9$ populations was not biologically relevant, so the value of $\mathrm{K}=3$ was chosen indicating that there were 3 genetically distinct groups (Figs. 3 and 4, Additional file 1: Figure S1, Additional file 2: Figure S2). Culex quinquefasciatus from Coachella California formed the first group, the Merced and Oroville California collections formed a second central valley group, and the last cluster was $C x$. pipiens from Washington (Fig. 3). The Structure analysis found that all individuals of $C x$. quinquefasciatus from Coachella California had a q value of $>0.8$ and were considered pure Cx. quinquefasciatus (Fig. 3), and most individuals of $C x$. pipiens from Washington had q values $>0.8$. From the Washington $C x$. pipiens population, there were 6 individuals considered admixed. Nearly all individuals from Merced classified their own cluster (97\%, 233/237 green) (Fig. 3). The $C x$. pipiens complex mosquitoes from the Merced habitats had 3\% (6/239) individuals that classified as pure Cx. pipiens (blue bars); one was from dairy, one from rural, two from suburban and two from urban areas (Fig. 3). None of the mosquitoes from Merced habitats classified as pure $C x$. quinquefasciatus. Oroville CA mosquitoes all classified as admixed (Fig. 3).

Subsequent Structure analyses compared individuals from each Merced habitat to those of the pure $C x$. pipiens and $C x$. quinquefasciatus populations. The Structure Harvester analysis for each habitat found the number of genetically distinct populations was $\mathrm{K}=2$; individuals from each Merced habitat shared alleles with both $C x$. pipiens and $C x$. quinquefasciatus, suggesting hybrid populations in each Merced habitat as well as in Oroville CA (Additional file 3: Figure S3a-f). In all habitat analyses and the Oroville analysis, the $\mathrm{q}$ values were $>0.9$ for all $C x$. quinquefasciatus from Coachella California, and $>0.9$ for all $C x$. pipiens from Washington. In the Structure analysis of mosquitoes from dairy habitat, most $(69 \%, 50 / 72)$ were admixed, while $31 \%$ (22/72) had q values $>0.9$ for assignment to pure $C x$. pipiens (Additional file 3: Figure S3a). For rural areas, most (88\%, 45/51) were admixed, and 12\% (6/51) of mosquitoes had q values $>0.9$ for assignment to $C x$. pipiens (Additional file 3 : Figure S3b). For suburban mosquito collections, most $85 \%$ (40/47) again were admixed, and 15\% (7/47) of mosquitoes were assigned to $C x$. pipiens (Additional file 3: Figure S3c). Urban mosquitoes followed a similar pattern; $89 \%$ of urban mosquitoes (31/35) were admixed, and 11\% (4/35) classified as $C x$. pipiens (Additional file 3: Figure S3d). Finally, wetlands had 100\% of individuals admixed (16/16) (Additional file 3: Figure S3e). The collection from Oroville California had $65 \%(11 / 17)$ of individuals admixed, and 35\% (6/17) classified as Cx. pipiens (Additional file 3: Figure S3f). An additional Structure and Structure Harvester analysis of the five Merced habitat-associated populations found the highest Evanno Delta $K$ value was at $K=8$, followed by $K=6$ and $K=4$; however, all Structure graphic files illustrating the probability of assignment for individuals for all of the aforementioned $\mathrm{K}$ values indicated one genetic cluster, and it was concluded that $K=1$.

The software New Hybrids was used to classify the ancestry of mosquitoes into groups, and determine whether they were parental species, F1 or F2 hybrids, or backcrosses to pure parental species. The analysis found the Coachella $\mathrm{Ca}$ mosquitoes were all classified 


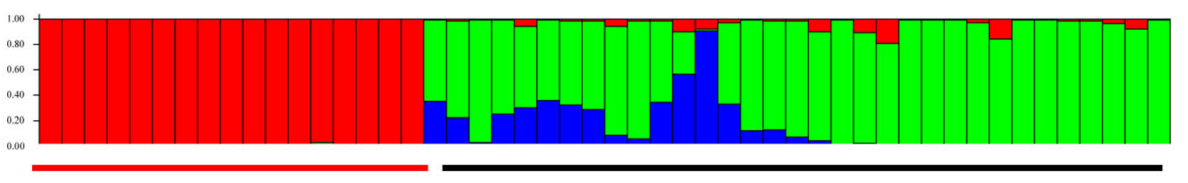

Cx. quin. COA

Dairy
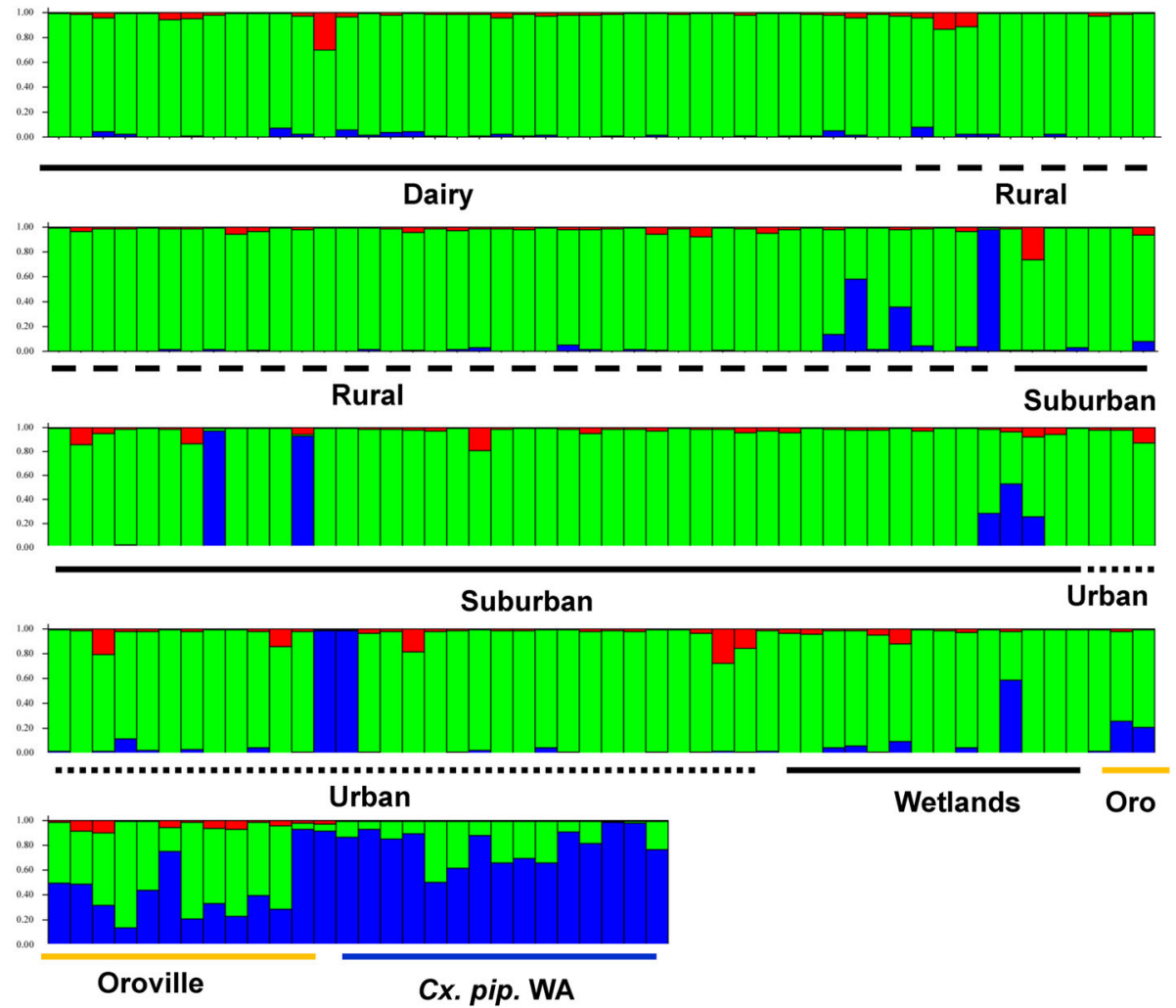

Fig. 3 A Structure 2.3.4 analysis of the 8 populations in the study was run using the following parameters: diploid individuals, 100,000 iterations, admixed data, and independent loci. Each vertical bar represents an individual mosquito. The $y$-axis shows the probability of an individual being assigned to one of the three genetic clusters. Red bars ( $C$ x. quin) represent the $C x$. quinquefasciatus individuals from Coachella, California. Green bars represent individuals from five habitat-associated populations from Merced; dairy, rural, suburban, urban and wetlands. Oroville (Oro) California is a mixture of green and blue bars, and blue bars ( $C$. pip) represent individuals of $C$. pipiens from Washington. Structure Harvester found that $K=3$; there were three genetically distinct populations

as pure Cx. quinquefasiatus (100\%), and the Washington mosquitoes were all classified as parental $C x$. pipiens, as expected (Table 3). Individuals from Merced dairies had $3 \%(2 / 72)$ assigned to pure $C x$. pipiens, $0 \%$ assigned to $C x$. quinquefasciatus, $0 \% \mathrm{~F} 1$ or F2 hybrids, and 97\% (70/72) assigned to hybrid backcrosses to pure Cx. pipiens. Rural areas in Merced had $2 \%(1 / 51)$ assigned to $C x$. pipiens, $0 \%$ to $C x$. quinquefasciatus, $0 \% \quad \mathrm{~F} 1$ and $\mathrm{F} 2$, and $98 \%$ (50/51) were hybrids backcrossed to $C x$. pipiens. Suburban areas in Merced had 100\% (47/47) classify as hybrids backcrossed to $C x$. pipiens, as did those from urban areas (35/35) and wetlands mosquitoes (16/16). Finally, Oroville had all but one $(16 / 17,94 \%)$ individual classified as hybrids backcrossed to $C x$. pipiens.

\section{Analysis of molecular variation (AMOVA)}

AMOVA of the $C x$. pipiens complex populations from four geographic areas found that collection region had a significant effect on genetic variation (Table 4), accounting for $12 \%$ of variation. Pairwise Fst values of genetic divergence between the four groups were significant $(P<0.01)$. The genetic distance estimate between $C x$. quinquefasciatus from Coachella and $C x$. pipiens from Washington was 0.360, Cx. quinquefasciatus from Coachella to Merced and Oroville were 0.164 and 0.232 , respectively, and $C x$. pipiens from Washington to Oroville and Merced was 0.108 and 0.106 , respectively (Table 5). Finally, Merced and Oroville which are both considered to be in the hybrid zone were less genetically distant (0.046) from each other than with the other populations. 


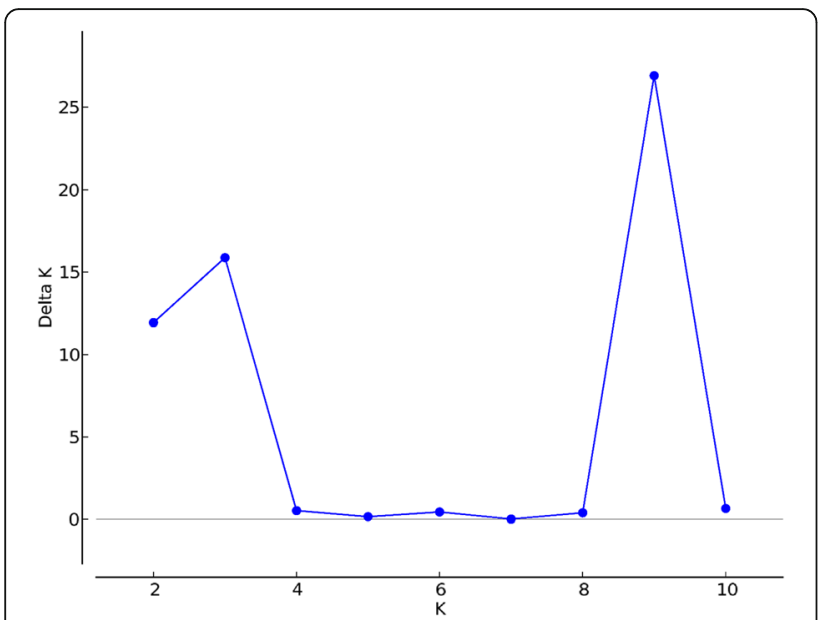

Fig. 4 Results from a Structure Harvester analysis of all eight populations. Structure Harvester uses the results from Structure to calculate the Delta $\mathrm{K}$ value, the change in likelihood, for the number of potential clusters. Structure Harvester calculated the most likely number of clusters was $3(K=3)$

Molecular variation between the five Merced habitat collections was significant as well (AMOVA, $P=0.008$ ), and accounted for $1 \%$ of the variation (Table 4 ). Pairwise genetic divergence tests found that individuals collected near dairies were significantly different than those collected near suburban and urban areas $(P<0.01)$ (Table 6). Pairwise comparisons among genetic divergence of other habitats were not significantly different.

The principal components analysis found that the first axis accounted for $61.82 \%$ of the variation, while the second and third axes explained $22.56 \%$ and $11.77 \%$ of the variation, respectively (Fig. 5). Examining axis 1, from left to right, there is a clear separation of the $C x$. pipiens and $C x$. quinquefasciatus populations into the top two quadrants (Fig. 5). The population from Oroville nearly clustered into the quadrant with $C x$. pipiens, and it was intermediate between the $C x$. pipiens population and the Merced habitat-associated populations. The second axis (y-axis) separates the $C x$. pipiens population from the
Table 4 Results of analysis of molecular variation (AMOVA) tests

\begin{tabular}{lllll}
\hline Source & $d f$ & Sum of squares & Variation (\%) & $P$ \\
\hline Among regions $^{\mathrm{a}}$ & 3 & 563.80 & 12 & 0.001 \\
Individuals within regions & 274 & $10,694.66$ & 88 & \\
Among habitats $^{\mathrm{b}}$ & 4 & 204.86 & 1 & 0.008 \\
Individuals within habitats & 224 & 8904.05 & 99 & \\
\hline
\end{tabular}

${ }^{\mathrm{a}} \mathrm{C} x$. pipiens complex populations from four regions including $C X$. quinquiefasciatus from Coachella CA, $C x$. pipiens complex from Merced and Oroville, and $C x$. pipiens from Washington

${ }^{\mathrm{b}}$ Populations of $C x$. pipiens complex from five Merced habitats

Abbreviation: $d f$ degrees of freedom

Merced habitat associated populations, which fall into a third quadrant, yet are positioned on axis 1 between $C x$. pipiens and Cx. quinquefasciatus (Fig. 5).

\section{Genetic distance and mantel test}

Nei's genetic distance was determined between all 8 populations in the study (Table 7). The largest genetic distance was between the $C x$. pipiens and $C x$. quinquefasciatus populations from Coachella California and Washington (0.134, 13\%). Culex quinquefasciatus from southern California was 0.064-0.067 distant from the five habitats in Merced and 0.087 distant from Oroville. Culex pipiens from Washington was 0.05 distant from Oroville, California and 0.042-0.49 distant from Merced populations. Finally, the Merced populations were $0.021-0.032$ distant from Oroville (Table 7). A Mantel test found no significant relationship between the genetic distance and geographic distance for the $C x$. pipiens populations $(r=0.686, P=0.110)$.

\section{Proportion of unique $C_{x}$. quinquefasciatus and $C_{x}$. pipiens alleles by habitat}

The proportion of alleles unique to the COA $C x$. quinquefasciatus and WA $C x$. pipiens populations were determined for each individual from the five Merced habitats (Table 8). The number of unique alleles in the pure $C x$. quinquefasciatus population which were not found in pure $C x$. pipiens was 73, while 122 unique alleles were found in the pure $C x$. pipiens which were not present in the pure

Table 3 Frequency of individuals in pure and hybrid classes from a New Hybrids analysis

\begin{tabular}{|c|c|c|c|c|c|c|}
\hline \multirow[b]{2}{*}{ Lineage } & \multirow{2}{*}{$\begin{array}{l}\text { Pure-bred A Cx. pipiens } \\
\text { Pure A }\end{array}$} & \multicolumn{4}{|c|}{ Hybrids } & \multirow{2}{*}{$\begin{array}{l}\text { Pure-bred B Cx.quinque } \\
\text { Pure B }\end{array}$} \\
\hline & & F1 & $\mathrm{F} 2$ & Backcross A & Backcross B & \\
\hline Cx. pipiens & $15 / 15$ & 0 & 0 & 0 & 0 & 0 \\
\hline Dairy & $2 / 72$ & 0 & 0 & $70 / 72$ & 0 & 0 \\
\hline Rural & $1 / 51$ & 0 & 0 & $50 / 51$ & 0 & 0 \\
\hline Suburban & 0 & 0 & 0 & $47 / 47$ & 0 & 0 \\
\hline Urban & 0 & 0 & 0 & $35 / 35$ & 0 & 0 \\
\hline Wetland & 0 & 0 & 0 & $16 / 16$ & 0 & 0 \\
\hline Oroville & $1 / 17$ & 0 & 0 & $16 / 17$ & 0 & 0 \\
\hline Cx. quinquefasciatus & 0 & 0 & 0 & 0 & 0 & $17 / 17$ \\
\hline
\end{tabular}


Table 5 Results of pairwise comparisons of genetic divergence estimates $\left(F_{\mathrm{ST}}\right)$ between $C$. pipiens complex populations

\begin{tabular}{llllll}
\hline & Population & 1 & 2 & 3 & 4 \\
\hline 1 & Cx. quinquefasciatus COA & 0 & & & \\
2 & Cx. pipiens complex Merced & $0.164^{*}$ & 0 & & \\
3 & Cx. pipiens complex ORO & $0.232^{*}$ & $0.046^{*}$ & 0 & \\
4 & CX. pipiens WA & $0.360^{*}$ & $0.106^{*}$ & $0.108^{*}$ & 0 \\
\hline
\end{tabular}

${ }^{*} P<0.01$ indicates comparison between populations is significant. All values were significant at $P<0.01$ after a Bonferroni correction

Abbreviations: COA Coachella CA, ORO Oroville CA, WA Lewis and Clarke Reservoir, WA

Cx. quinquefasciatus population. For each of the five habitat-associated populations in Merced, the average number of $C x$. quinquefasciatus alleles in all individuals in each populations was 9 , while the average number of $C x$. pipiens alleles was 15; Oroville individuals had an average of 10 unique alleles from $C x$. quinquefasciatus and 20 from $C x$. pipiens. The proportion of unique $C x$. quinquefasciatus alleles in Merced populations ranged from an average of $38 \%$ in dairy and urban populations up to $42 \%$ in rural populations (Table 8), while the proportion of unique $C x$. pipiens alleles ranged from 0.58 in rural areas to 0.62 in dairies (Table 8). Within each habitat, a Chisquare test found that the proportion of $C x$. pipiens: $C x$. quinquefasciatus varied significantly from 1:1 $(P<0.05)$ (Table 8), with a lower proportion of alleles contributed from $C x$. quinquefasciatus than from $C x$. pipiens. A oneway ANOVA found there was no significant difference in the proportion of unique $C x$. quinquefasciatus alleles among all 5 habitat-associated populations $\left(F_{(4,265)}=0.65\right.$, $P=0.623)$. The Oroville population had a larger proportion of $C x$. pipiens alleles than of $C x$. quinquefasciatus $\left(\chi^{2}\right.$ $=38.72 ; d f=1 ; P<0.001)(C x$. pipiens $72 \%, C x$. quinquefasciatus 28\%) (Table 8).

Merced habitat-associated populations and the Oroville population were examined as well to determine their unique alleles. Merced habitats had three alleles at relatively high frequency, which were found in nearly half the individuals in 2 or 3 habitats, yet they were not present in the Oroville population, nor in the $C x$. pipiens or $C x$. quinquefasciatus populations. One of these loci was present in 34, 30, 30, 15 and 9 individuals of dairy

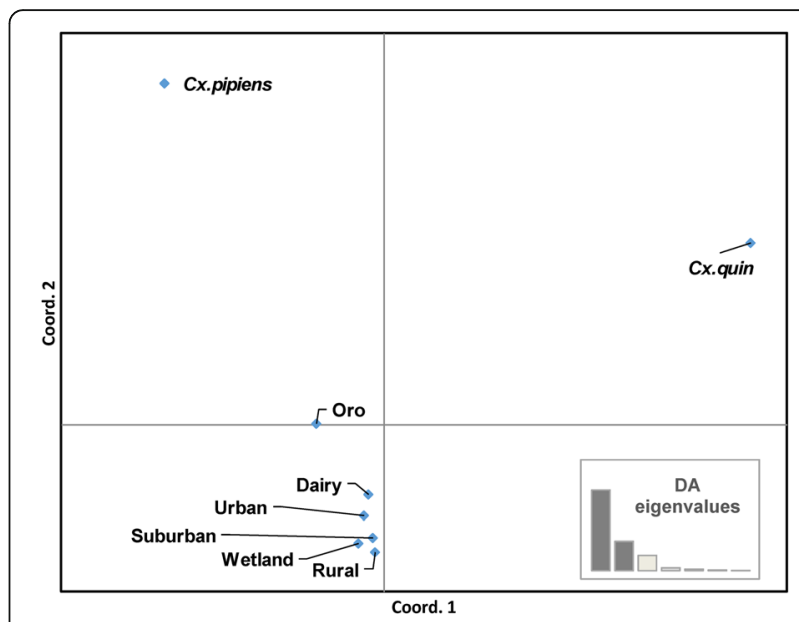

Fig. 5 Principal components analysis using genetic distance output of AMOVA of the eight populations in the study. The eight populations included pure $C x$. pipiens from Washington, pure $C X$. quinquefasciatus (CX. quin) from Coachella, California, a population from Oroville (Oro) $\mathrm{Ca}$, and five habitat-associated populations from Merced

(D), rural (R), suburban (S), urban (U) and wetland (W) habitat collections, respectively, while a second and third unique loci were found in 31D, 21R, 3S, $4 \mathrm{U}, 7 \mathrm{~W}$ and 1D, 16R, 13S, $6 \mathrm{U}$ and $0 \mathrm{~W}$ individuals of the same habitats. In additional, there were fifteen alleles found at a very low frequency (in 1-10 individuals) in several habitats in Merced, and which were also not found in the Oroville, $C x$. pipiens, or the $C x$. quinquefasciatus populations. The Mcheza analysis to examine loci under selection found 10 loci under putative positive selection, and 36 loci possibly under balancing selection (Fig. 6).

\section{Discussion}

The Cx. pipiens species complex consists of morphologically similar, but genetically, behaviorally and ecologically distinct populations. Numerous studies have considered whether $C x$. pipiens and $C x$. quinquefasciatus are distinct species or subspecies of $C x$. pipiens, especially with respect to variation in host feeding preference and reproductive diapause $[49,50]$. Previous studies used the DV/D ratio of the genitalia to separate these two groups and their hybrids [15], but environmental

Table 6 Results of pairwise comparisons of genetic divergence estimates $\left(F_{S T}\right)$ from five Merced habitats

\begin{tabular}{llllll}
\hline & Populations in Merced habitat & 1 & 2 & 3 & 4 \\
\hline 1 & Dairy & 0 & & & \\
3 & Rural & $0.004 \mathrm{~ns}$ & 0 & 0 & \\
4 & Suburban & $0.007^{*}$ & $0.001 \mathrm{~ns}$ & 0 & $0.006 \mathrm{~ns}$ \\
5 & Urban & $0.011^{*}$ & $0.008 \mathrm{~ns}$ & $0.010 \mathrm{~ns}$ & $0.008 \mathrm{~ns}$ \\
\hline
\end{tabular}

${ }^{*} P<0.01$ indicates comparison between populations is significant. Results were corrected for multiple comparisons with a Bonferroni correction Abbreviation: ns not significant at $P<0.01$ 
Table 7 Nei's genetic distance among populations. Populations from Coachella, California (COA), Merced County populations from dairy, rural, suburban (Suburb.), urban and wetland (Wet.) areas, Oroville California, and Lewis and Clark Reservoir, Washington (L\&C, WA). Locations of all populations in Table 1 and Fig. 2

\begin{tabular}{lllllllll}
\hline & COA & Dairy & Rural & Suburb. & Urban & Wet. & Oroville & L\&C,WA \\
\hline COA. & - & 0.064 & 0.064 & 0.065 & 0.067 & 0.067 & 0.087 & 0.134 \\
Dairy & & - & 0.006 & 0.007 & 0.009 & 0.012 & 0.021 & 0.042 \\
Rural & & & - & 0.006 & 0.009 & 0.014 & 0.027 & 0.048 \\
Suburb & & & & - & 0.009 & 0.014 & 0.028 & 0.049 \\
Urban & & & & - & 0.014 & 0.032 & 0.045 \\
Wetland & & & & & - & 0.030 & 0.048 \\
Oroville & & & & & & - & 0.050 \\
L\&C, WA & & & & & & & & - \\
\hline
\end{tabular}

conditions and food availability could influence the size of individuals in a population, and subsequent work found that DV/D ratios do not consistently correspond to genetic differences in populations $[3,5]$. In the case of a species complex, molecular markers are helpful and could be more accurate to separate populations within a species group. Different insect orders vary in the level of genetic variation considered sufficient to warrant separate species status [51, 52]. A study of Culex annulirostris in Australia and Papua New Guinea found morphologically similar but genetically divergent lineages just 3\% divergent, one able to transmit Japanese encephalitis virus (JEV) while another lineage did not [53]. In this study, $C x$. pipiens and $C x$. quinquefasciatus had a genetic distance of 0.134 (13\%) indicating moderate genetic divergence, which supports that these two groups are distinct species [49].

The Structure analysis of all eight populations considered in this study found $\mathrm{K}=3$ (three distinct groups) with Merced and Oroville populations in the Central Valley more similar to each other than to either the $C x$. pipiens or $C x$. quinquefasciatus populations. The AMOVA analysis found $12 \%$ of molecular variation among the eight populations in this study, similar to the $11 \%$ and $10 \%$ variation observed in two previous studies of $C x$. pipiens populations in the Midwest and in California, USA [13, 20].

Table 8 The proportion of fixed unique alleles derived from pure populations of $C x$. pipiens and $C x$. quinquefasciatus

\begin{tabular}{llllll}
\hline Habitat & $\begin{array}{l}\text { No. of } \\
\text { individuals }\end{array}$ & $\begin{array}{l}\text { Proportion of } \begin{array}{l}\text { Proportion of } \\
\text { alleles }\end{array} \\
\text { alens }\end{array}$ & $\begin{array}{l}x^{2}- \\
\text { Cx. quinquefasciatus }\end{array}$ & $\begin{array}{l}\text { P-value } \\
\text { allue }\end{array}$ \\
\hline Dairy & 72 & 0.620 & 0.380 & 11.49 & $0.0007^{*}$ \\
Rural & 54 & 0.580 & 0.420 & 5.12 & $0.024^{*}$ \\
Suburban & 47 & 0.600 & 0.400 & 8.00 & $0.005^{*}$ \\
Urban & 35 & 0.620 & 0.380 & 11.49 & $0.0007^{*}$ \\
Wetlands & 16 & 0.625 & 0.385 & 10.58 & $0.001^{*}$ \\
\hline
\end{tabular}

${ }^{\overline{ } P} P<0.05$
The populations in this study from the $C x$. pipiens complex hybrid zone had genetic distances between $C x$. pipiens and $C x$. quinquefasciatus in the range of $0.04-0.05$, close to $5 \%$, suggesting the stable interbreeding hybrid population is undergoing significant divergence from $C x$. pipiens and $C x$. quinquefasciatus. This is also supported by the finding of a number of loci putatively under positive selection (Fig. 6). Hybrid offspring of other species are often sterile, but the $C x$. pipiens complex hybrids in the Central Valley are fertile and can interbreed with both $C x$. pipiens and $C x$. quinquefasciatus [13]. An interesting biological attribute of $C x$. pipiens and $C x$. quinquefasciatus is their ability to hybridize in areas where they have been introduced, yet not to hybridize in South Africa where they are thought to have originated, and where they occur together sympatrically [4].

A stable interbreeding population in the hybrid zone of California has been observed previously [13]. A study of the population genetic structure of the $C x$. pipiens complex from southern to northern California and also including Washington found four genetically distinct groups, with two clusters in the Central Valley. One Central Valley California population which occurred in collections from northern California near Shasta and South to Turlock was called Cluster X, which Merced Cx. pipiens hybrids may belong to. The $\mathrm{F}_{\mathrm{ST}}$ pairwise genetic divergence estimates in this study for $C x$. quinquefasciatus from Coachella and $C x$. pipiens from Oroville were 0.236, while those of Kothera et al. [13] for $C x$. quinquefasciatus from Coachella and $C x$. pipiens from Shasta were 0.27 . From the Coachella population to that of Merced, the pairwise genetic divergence estimate was 0.164, while in Kothera et al. [13] their measurements for two Coachella populations to Turlock ranged from 0.174 to 0.187 . The study by Kothera et al. [13] used microsatellites, while this study determined genetic structure using AFLPs. The similarity of results between the two studies supports the utility of both types of molecular markers for population comparisons.

We sampled different ecological habitats of Merced to determine whether $C x$. pipiens and $C x$. quinquefasciatus could occur in close proximity in different habitats, since they were found to occur together in previous studies of the Central Valley of California, as well as in South Africa [3-5, 22]. In Merced, the majority of individuals sampled were hybrid mosquitoes; however, dairy populations had more pure $C x$. pipiens individuals. Populations in all five habitats had more alleles specific to the $C x$. pipiens population from Washington than alleles unique to $C x$. quinquefasciatus from Coachella, even though the geographical distance between Merced and Washington is almost twice the distance as between Merced and Coachella, California ( $\sim 700$ miles vs $\sim 400$ miles). Another study of $C x$. pipiens through the middle of the USA similarly found that in Memphis, near the center of the hybrid zone, nearly all individuals sampled were hybrids [20]. 


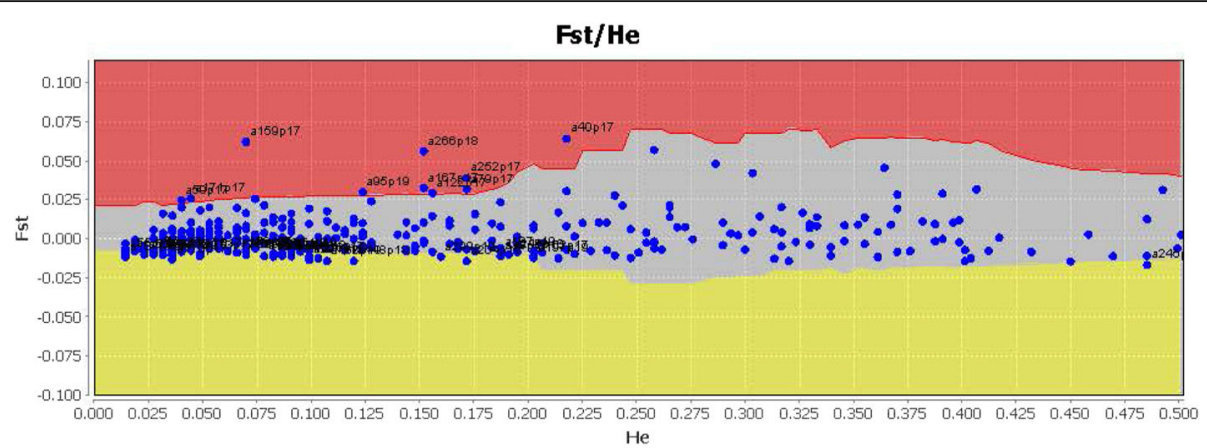

Fig. 6 Loci under possible positive selection shown in red, neutral selection in the gray region, and those under balancing selection are shown in the yellow region, using Mcheza software

Habitats where $C x$. pipiens complex mosquitoes were collected in Merced had a small but significant influence on the genetic composition of hybrids. AMOVA analysis revealed $1 \%$ of genetic variation in Merced collections due to habitats, with dairy collections being genetically divergent from rural and suburban habitats. The analysis which examined the number of unique $C x$. pipiens or $C x$. quinquefasciatus alleles in the Merced populations found that on average each habitat had a similar proportion of $C x$. pipiens: $C x$. quinquefasciatus alleles, with rural collections having a trend toward a higher percentage of $C x$. quinquefasciatus alleles (42\%); perhaps this small but statistically insignificant difference is enough to influence where human WNv cases occur.

There were several alleles found in the Merced populations at relatively high frequency, and fifteen alleles found in the Merced populations at low frequency, none of which were found in the $C x$. pipiens, $C x$. quinquefasciatus or the Oroville populations. The principal components analysis found that $C x$. pipiens and $C x$. quinquefasciatus fell into separate quadrants. However, the Merced habitat associated populations were in a third quadrant, but with respect to the $\mathrm{x}$-axis, they were in close proximity to being intermediate between $C x$. pipiens and $C x$. quinquefasciatus. There are several explanations as to why the Merced hybrids are not placed exactly in between the two upper quadrants with $C x$. pipiens and $C x$. quinquefasciatus. The Merced populations consist of many more individuals than included in the $C x$. pipiens or $C x$. quinquefasciatus populations, which might have captured some alleles not present in the smaller parent populations. However, the Oroville population was similar sized to the $C x$. pipiens and $C x$. quinquefasciatus populations, and it lies between the $C x$. pipiens quadrant and the third quadrant with the Merced populations. It is unlikely that the Merced mosquito populations are misidentified; there are no known mosquito species in the Merced area which could be confused morphologically with the Cx. pipiens complex. The placement of the Merced populations in the third quadrant in the principal component analysis suggests a genetic contribution from a closely related member of the $C x$. pipiens complex, perhaps $C x$. pipiens molestus.

Previous studies of the Cx. pipiens complex in the Merced area did not consider the presence of $C x$. pipiens molestus. We focused this study on whether $C x$. quinquefasciatus or Cx. pipiens complex hybrids might be more common in a particular habitat; for that reason, mosquito collections were focused outdoors in aboveground habitats where it was believed that $C x$. pipiens molestus would not commonly occur. However, several recent studies including have found $C x$. pipiens molestus hybrids more widespread and in more habitats than previously expected $[8,13]$. In this study, Merced collections did not include sewers or underground structures such as basements which Cx. pipiens molestus was traditionally considered to inhabit. Future studies in Merced and the southern San Joaquin Valley should collect underground in sewers and basements along with other outdoor habitats including in animal shelters, to determine where Cx. pipiens molestus may be present.

The genetic composition of hybrids is just one factor that could influence where $\mathrm{WNv}$ positive mosquitoes are abundant. Most hybrids were of similar genetic composition, consisting primarily of hybrids backcrossed to $C x$. pipiens. Thus, they may be likely to have similar vector capacities and transmission rates of West Nile virus. However, this would need to be determined experimentally to ascertain with certainly the ability of hybrids backcrossed to parental species to transmit West Nile virus.

Temperature has been suggested as a limiting environmental factor which affects the distribution of $C x$. pipiens and $C x$. quinquefasciatus along with the extent of their hybrid zone [5]. Warmer winters in southern latitudes allow $C x$. quinquefasciatus to overwinter as reproductive adults, which contributes to higher $C x$. quinquefasciatus abundance in the spring, more generations per year, and a longer $\mathrm{WNv}$ disease transmission season. In the Central Valley of California, cooler winter temperatures may prevent $C x$. quinquefasciatus from surviving. In northern latitudes where $C x$. pipiens is abundant, adults undergo reproductive diapause and are less numerous in spring. In 
addition, $C x$. pipiens have a low vertical transmission rate of West Nile virus, making the disease slower to increase each year in local mosquito populations [5]. Some have suggested the southern range of the hybrid zone has moved North of $39^{\circ}$ latitude [20]. The Oroville population in this study which was collected near $39^{\circ}$ latitude was found to be a hybrid population, not pure Cx. pipiens. Models of climate warming and increasing average temperatures predict the northern expansion of $C x$. pipiens complex hybrids, and an increasing number of human West Nile virus cases [53]. Studies have demonstrated variation in vector capacity of $C x$. pipiens complex populations, with hybrids having higher transmission rates than non-hybrids, and pure $C x$. quinquefasciatus having among the highest transmission rates $[5,21]$.

\section{Conclusions}

This study investigated the hybrid composition of $C x$. pipiens complex populations from five Merced habitats to determine whether some habitats had more hybrids than others. Nearly all mosquitoes collected were hybrids backcrossed to Cx. pipiens; collections from dairies had more individuals than the other habitats that classified as pure $C x$. pipiens, while none of the habitats in Merced or Oroville had mosquitoes that classified as pure $C x$. quinquefasciatus. Mosquitoes collected in dairies were genetically divergent from those collected in suburban and urban areas. All hybrids had a larger proportion of alleles shared with the pure $C x$. pipiens population than with the pure $C x$. quinquefasciatus population. Results also suggest the presence of $C x$. pipiens molestus in Merced, but this needs to be confirmed. The $C x$. pipiens complex in the Merced shared more alleles with the pure $C x$. pipiens population, even though it was more geographically distant from the pure $C x$. pipiens populations than from the pure $C x$. quinquefasciatus population. Cold winter temperatures may limit the northern introgression of $C x$. quinquefasciatus alleles into the hybrid zone. Future studies might examine the ability of hybrids backcrossed to $C x$. pipiens and $C x$. quinquefascitus to transmit West Nile virus.

\section{Additional files}

Additional file 1: Figure S1. Results from a Structure Harvester analysis of all eight populations of the Cx. pipiens complex in this study. Each row shows the probability of $\mathrm{K}$ populations and delta $\mathrm{K}$. The most likely number of populations was $K=3$. (TIFF $2681 \mathrm{~kb}$ )

Additional file 2: Figure S2. The results from Distruct using output from Structure for $\mathrm{K}=3$ populations. (TIFF $2317 \mathrm{~kb}$ )

Additional file 3: Figure S3. Structure analyses for each of five Merced habitat-associated populations and for the Oroville California population individually compared to Cx. quinquefasciatus from Coachella, California and to $C x$. pipiens from Washington. Structure was run using the following parameters: diploid individuals, 100,000 iterations, admixed data, and independent loci. Each vertical bar represents an individual mosquito. Structure Harvester found $\mathrm{K}$ $=2$ clusters. The $y$-axis shows the probability of an individual being assigned to one of the two genetic clusters. Panels include $\mathbf{a}$ dairy (D) collections, $\mathbf{b}$ rural (R) habitat collections, c suburban (S) collections, d urban (U) collections, e wetland $(W)$ collections, and $\mathbf{f}$ Oroville California, each compared to pure $C X$. quinquefasciatus and Cx. pipiens populations. (PDF 659 kb)

\section{Acknowledgments}

We thank the staff at Merced County Mosquito Abatement District (MCMAD) for assisting in collecting samples and for assisting with identification of Culex pipiens complex species, especially Jason Bakken and Arlilla Bueno. Ashley Valley and Maria Martinez of the University of California Merced helped with DNA extraction and AFLP work. Additional mosquito collections were obtained by Lindsay Robson, Kylie McMillan, and Austyn Smith. We thank Coachella Valley Mosquito and Vector Control District, Butte County Mosquito and Vector Control District and Benton County Mosquito Control District Washington for contributing insects.

\section{Funding}

This project was supported by the Merced County Mosquito Abatement District (MCMAD) in Merced, California, United States. MCMAD supported the cost of mosquito collections, genetic work, and UC Merced students who worked on the project. The project was also supported by the University of California Merced, who contributed to the cost of research supplies and supporting undergraduate student assistants.

\section{Availability of data and materials}

The data supporting the conclusions of this article are included within the article and its additional files. The datasets used and analyzed during the current study available from the corresponding author upon reasonable request.

\section{Authors' contributions}

Study design: ALJ and Al. Data collection: AL, EM, PTH and Al. Data analysis: AL, EM and PTH. Manuscript preparation: ALJ. All authors read and approved the final manuscript.

Ethics approval and consent to participate

Not applicable.

Consent for publication

Not applicable.

\section{Competing interests}

The authors declare that they have no competing interests.

\section{Publisher's Note}

Springer Nature remains neutral with regard to jurisdictional claims in published maps and institutional affiliations.

\section{Author details}

${ }^{1}$ Public Health, University of California Merced, 5200 North Lake Road, Merced, CA 95343, USA. ²Department of Microbiology and Immunology, Life Sciences Institute, University of British Columbia, Vancouver, BC V6T 1Z3, Canada. ${ }^{3}$ Santa Clara County Vector Control District, 1580 Berger Dr, San Jose, CA 95112, USA. ${ }^{4}$ Merced County Mosquito Abatement District, 3478 Beachwood Dr, Merced, CA 95348, USA.

Received: 22 February 2017 Accepted: 17 December 2017

Published online: 04 January 2018

References

1. Goddard LB, Roth AE, Reisen WK, Scott TW. Vector competence of California mosquitoes for West Nile virus. Emerg Infect Dis. 2002;8:1385-91.

2. McLean RG, Ubico SR, Docherty DE, Hansen WR, Sileo L, McNamara TS. West Nile virus transmission and ecology in birds. Ann N Y Acad Sci. 2001;951:54-7.

3. Tabachnick WJ, Powell JR. Genetic analysis of Culex pipiens populations in the central valley of California. Ann Entomol Soc Am. 1983;76:715-20.

4. Cornel AJ, McAbee RD, Rasgon J, Stanich M, Scott TW, Coetzee M. Differences in extent of genetic introgression between sympatric Culex pipiens and Culex quinquefasciatus (Diptera: Culicidae) in California and South Africa. J Med Entomol. 2003:40:36-51.

5. McAbee RD, Green EN, Holeman J, Christiansen J, Frye N, Dealey K, et al. Identification of Culex pipiens complex mosquitoes in a hybrid zone of West 
Nile virus transmission in Fresno County, California. Am J Trop Med Hyg. 2008;78:303-10.

6. Sanogo YO, Kim CH, Lampman R, Halvorsen JG, Gad AM, Novak RJ. Identification of male specimens of the Culex pipiens complex (Diptera: Culicidae) in the hybrid zone using morphology and molecular techniques. J Med Entomol. 2008:45:203-9.

7. Turell MJ, Dohm DJ, Sardelis V, O'Guinn ML, Andreadis TG, Blow JA. An update on the potential of North America mosquitoes (Diptera: Culicidae) to transmit West Nile virus. J Med Entomol. 2005:42:57-62.

8. Gomes B, Sousa CA, Vicente JL, Pinho L, Calderon I, Arez E, et al. Feeding patterns of molestus and pipiens forms of Culex pipiens (Diptera: Culicidae) in a region of high hybridization. Parasit Vectors. 2013;6:93.

9. Reisen WK, Meyer RP, Tempelis CH, Spoehel JJ. Mosquito abundance and bionomics in residential communities in Orange and Los Angeles counties, California. J Med Entomol. 1990;27:356-67.

10. Molaei G, Andreadis TG, Armstrong PM, Bueno R Jr, Dennett JA, Real SV, et al. Host feeding pattern of Culex quinquefasciatus (Diptera: Culicidae) and its role in transmission of West Nile virus in Harris County, Texas. Am J Trop Med Hyg. 2007;77:73-81.

11. Montgomery MJ, Thiemann T, Macedo P, Brown DA, Scott TW. Bloodfeeding patterns of the Culex pipiens complex in Sacramento and Yolo countries, California. J Med Entomol. 2011;48:398-404.

12. Lee Y, Seifert SN, Nieman CC, McAbee RD, Goodel P, Fryxell RT, et al. High degree of single nucleotide polymorphisms in California Culex pipiens (Diptera: Culicidae) sensu lato. J Med Entomol. 2012;49:299-306.

13. Kothera L, Nelms BM, Reisen WR, Savage HM. Population genetic and admixture analyses of Culex pipiens complex (Diptera: Culicidae) populations in California, United States. Am J Trop Med Hyg. 2013;89:1154-67.

14. Osório HC, Ze-ze L, Amaro F, Nunes A, Alves MJ. Sympatric occurrence of Culex pipiens (Diptera, Culicidae) biotypes pipiens, molestus and their hybrids in Portugal, Western Europe: feeding patterns and habitat determinants. Med Vet Entomol. 2014;28:103-9.

15. Barr RA. The distribution of Culex p. pipiens and CX. p. quinquefasciatus in North America. Am J Trop Med Hyg. 1957;6:153-65.

16. Smith JL, Fonseca DM. Rapid assays for identification of members of the Culex pipiens complex, their hybrids, and other sibling species (Diptera: Culicidae). Am J Trop Med Hyg. 2004;70:339-45.

17. Bahnck CM, Fonseca DM. Rapid assay to identify the two genetic forms of Culex pipiens L. (Diptera: Culicidae) and hybrid populations. Am J Trop Med Hyg. 2006;75:251-5.

18. Kasai S, Komagata O, Tomita T, Sawabe K, Tsuda Y, Kurahashi H, et al. PCRbased identification of Culex pipiens complex collected in Japan. Jpn J Infect Dis. 2008:61:184-91.

19. Fonseca DM, Keyghobadi N, Malcolm CA, Mehmet C, Schaffner F, Motoyoshi M, et al. Emerging vectors in the Culex pipiens complex. Science. 2004;303:1535-8.

20. Kothera L, Zimmerman EM, Richards CM, Savage HM. Microsatellite characterization of subspecies and their hybrids in Culex pipiens complex (Diptera: Culicidae) mosquitoes along a north-south transect in the central United States. J Med Entomol. 2009;46:236-48.

21. Ciota AT, Chin PA, Kramer LD. The effect of hybridization of Culex pipiens complex mosquitoes on transmission of West Nile virus. Parasit Vectors. 2013;6:305.

22. Vaidyanathan R, Scott TW. Geographic variation in vector competence for West Nile virus in the Culex pipiens (Diptera: Culicidae) complex in California. Vector Borne Zoonot Dis. 2007;7:193-8.

23. Savage HM, Anderson M, Gordon E, McMillen L, Colton L, Charnetzky D, et al. Oviposition activity patterns and West Nile virus infection rates for members of the Culex pipiens complex at different habitat types within the hybrid zone, Shelby County, TN, 2002 (Diptera: Culicidae). J Med Entomol 2006:43:1227-38

24. Vialatte A, Dedryver CA, Simon JC, Galman M, Plantegenest M. Limited genetic exchange between populations of an insect pest living on uncultivated and related cultivated host plants. Proc Royal Soc Lond B. 2005;272:1075-82.

25. Nosil P. Ecological Speciation. Oxford: Oxford University Press; 2012.

26. Takken W, Verhulst N. Host preferences of blood-feeding mosquitoes. Annu Rev Entomol. 2013;58:433-53.

27. Vogels CBF, Möhlmann TWR, Melsen D, Favia G, Wennergren U, Koenraadt CJM. Latitudinal diversity of Culex pipiens biotypes and hybrids in farm, periurban, and wetland habitats in Europe. PLoS One. 2016;11:e0166959.
28. Bowden SE, Magori K, Drake JM. Regional differences in the association between land cover and West Nile virus disease incidence in humans in the United States. Am J Trop Med Hyg. 2011;84:234-8.

29. US Census Bureau: Geographic terms and concepts. 2010. https://www. census.gov/geo/reference/terms.html Accessed 27 Nov 2016.

30. Forsyth A. Defining suburbs. J Plan Lit. 2012;27:270-81.

31. EPA-Environmental Protection Agency. What are wetlands? 2016. https:// www.epa.gov/wetlands/what-wetland Accessed 27 Nov 2016.

32. Meyer R, Reisen WK. Integrated mosquito surveillance program guidelines for California. Sacramento, CA, USA: Mosquito Vector and Control Association of California; 2003.

33. Meyer RP. Guide to the mosquitoes of California. III. Central Valley and western sierra. Sacramento, CA, USA: Mosquito and Vector Control Association of California; 1993.

34. Qiagen. DNeasy tissue handbook. Valencia, CA, USA: Qiagen; 2006.

35. Vos PR, Hogers M, Bleeker M, Reijans T, Van de Lee M, Hornes A, et al. AFLP: a new technique for DNA fingerprinting. Nucleic Acids Res. 1995;23:4407-14.

36. Joyce AL, Hunt RE, Vinson SB, Bernal JS, Schulthess F, Medina RF. Geographic variation in male courtship acoustics and genetic divergence of populations of the Cotesia flavipes (hymenoptera: Braconidae) species complex. Entomol Exp Appl. 2010;137:153-64.

37. Saunders J, Mischke S, Hemeida AA. The use of AFLP techniques for DNA fingerprinting in plants. A-1910A. Beckman coulter application notes; 2001. Fullerton, CA, USA: Beckman Coulter; 2001.

38. Zhang $H$, Hare MP. Identifying and reducing AFLP genotyping error: an example of tradeoffs when comparing population structure in broadcast spawning versus brooding oysters. Heredity. 2012;108:616-25.

39. Pritchard JK, Wen $X$, Falush D. Documentation for structure software: version 2.2. 2007. https://web.stanford.edu/group/pritchardlab/software/structure22/ readme.pdf Accessed 13 Dec 2017.

40. Pritchard JK, Stephens M, Donnelly P. Inference of population structure using multilocus genotype data. Genetics. 2000;155:945-59.

41. Evanno G, Regnaut $\mathrm{S}$, Goudet J. Detecting the number of clusters of individuals using the software STRUCTURE: a simulation study. Mol Ecol. 2005:14:2611-20.

42. Earl DA, von Holdt BM. STRUCTURE HARVESTER: a website and program for visualizing STRUCTURE output and implementing the Evanno method. Conserv Genet Resources. 2012;4:359-61.

43. Anderson EC, Thompson EAA. Model-based method for identifying species hybrids using multilocus genetic data. Genetics. 2002;160:1217-29.

44. Excoffier L, Smouse PE, Quattro JM. Analysis of molecular variance inferred from metric distances among DNA haplotypes, application to human mitochondrial DNA restriction data. Genetics. 1992;131:479-91.

45. Peakall R, Smouse PE. GenAlEx 6: genetic analysis in excel. Population genetic software for teaching and research. Mol Ecol Notes. 2006;6:288-95.

46. Felsenstein J. PHYLIP - Phylogeny inference package (version 3.2). Cladistics. 1989;5:164-6.

47. Siegel S, Castellan NJ Jr. Nonparametric statistics for the behavioral sciences. 2nd ed. New York, USA: McGraw Hill; 1988.

48. Antao T, Beaumont MA. Mcheza: a workbench to detect selection using dominant markers. Bioinformatics. 2011;27:1717-8.

49. Harbach R. Culex pipiens: species versus species complex-taxonomic history and perspective. J Am Mosq Contr Assoc. 2012;28(4S):10-23.

50. Reisen WK. The contrasting bionomics of Culex mosquitoes in the western North America. J Am Mosq Contr Assoc. 2012;28(45):82-91.

51. Hebert PDN, Penton EH, Burns JM, Janzen DH, Hallwachs W. Ten species in one: DNA barcoding reveals cryptic species in the Neotropical skipper butterfly Astraptes fulgerator. Proc Natl Acad Sci USA. 2004;101:14812-7.

52. Cywinska A, Hunter FF, Hebert PDN. Identifying Canadian mosquito species through DNA barcodes. Med Vet Entomol. 2006;20:413-24.

53. Hemmerter S, Slapeta J, van den Hurt AF, Cooper RD, Whelan PI, Russell RC, et al. A curious coincidence: mosquito biodiversity and the limits of the Japanese encephalitis virus in Australasia. BMC Evol Biol. 2007;7:100. 